\title{
RESEARCH
}

Open Access

\section{Head-to-head comparison between the EQ-5D-5L and the EQ-5D-3L in general population health surveys}

Marc Martí-Pastor ${ }^{1,2,3}$, Angels Pont ${ }^{1,2}$, Mónica Ávila1,2,4, Olatz Garin ${ }^{1,2,4^{*}}$, Gemma Vilagut ${ }^{1,2,4}$, Carlos G. Forero ${ }^{1,2,4}$, Yolanda Pardo 1,2,3, Ricard Tresserras ${ }^{4,5}$, Antonia Medina-Bustos ${ }^{5}$, Oriol Garcia-Codina ${ }^{5}$, Juan Cabasés ${ }^{6}$, Luis Rajmil ${ }^{1,2,7}$, Jordi Alonso ${ }^{1,2,4}$ and Montse Ferrer ${ }^{1,2,3^{*}}$ (D)

\begin{abstract}
Background: The EQ-5D has been frequently used in national health surveys. This study is a head-to-head comparison to assess how expanding the number of levels from three (EQ-5D-3L) to five in the new EQ-5D-5L version has improved its distribution, discriminatory power, and validity in the general population.

Methods: A representative sample ( $N=7554)$ from the Catalan Health Interview Survey 2011-2012, aged $\geq 18$, answered both EQ-5D versions, and we evaluated the response redistribution and inconsistencies between them. To assess validity of this redistribution, we calculated the mean of the Visual Analogue Scale (VAS), which measures perceived health. The discriminatory power was examined with Shannon Indices, calculated for each dimension separately. Spanish preference value sets were applied to obtain utility indices, examining their distribution with statistics of central tendency and dispersion. We estimated the proportion of individuals reporting the best health state in EQ-5D-5L and EQ-5D-3L within groups of specific chronic conditions and their VAS mean.

Results: A very small reduction in the percentage of individuals with the best health state was observed, from $61.8 \%$ in EQ-5D-3L to $60.8 \%$ in EQ-5D-5L. In contrast, a large proportion of individuals reporting extreme problems in the $3 \mathrm{~L}$ version moved to severe problems (level 4 ) in the $5 \mathrm{~L}$ version, particularly for pain/discomfort (75.5\%) and anxiety/ depression (66.4\%). The average proportion of inconsistencies was $0.9 \%$. The pattern of the perceived health VAS mean confirmed the hypothesis established a priori, supporting the validity of the observed redistribution. Shannon index showed that absolute informativity was higher in the $5 \mathrm{~L}$ version for all dimensions. The means (SD) of the Spanish EQ5D-3L and EQ-5D-5L indices were $0.87(0.25)$ and $0.89(0.22)$. The proportion of individuals with the best health state within each specific chronic condition was very similar, regardless of the EQ-5D version ( $\leq 30 \%$ in half of the 28 chronic conditions).

Conclusion: Although the proportion of individuals with the best possible health state is still very high, our findings support that the increase of levels provided by the EQ-5D-5L contributed to the validity and discriminatory power of this new version to measure health in general population, as in the national health surveys.
\end{abstract}

Keywords: Quality of life, Health survey, Validity and reliability, Perceived health

\footnotetext{
* Correspondence: ogarin@imim.es; mferrer@imim.es

${ }^{1}$ IMIM (Hospital del Mar Medical Research Institute), Health Services Research

Group, Doctor Aiguader, 88, 08003 Barcelona, Spain

Full list of author information is available at the end of the article
}

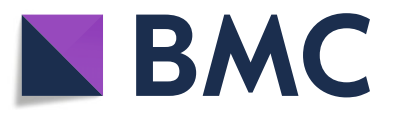

(c) The Author(s). 2018 Open Access This article is distributed under the terms of the Creative Commons Attribution 4.0 International License (http://creativecommons.org/licenses/by/4.0/), which permits unrestricted use, distribution, and reproduction in any medium, provided you give appropriate credit to the original author(s) and the source, provide a link to the Creative Commons license, and indicate if changes were made. The Creative Commons Public Domain Dedication waiver (http://creativecommons.org/publicdomain/zero/1.0/) applies to the data made available in this article, unless otherwise stated. 


\section{Background}

Health-related quality of life has been gaining importance in research, clinical practice and health planning $[1,2]$ by providing complementary information to health indicators based on morbidity and mortality. This is especially relevant to describe health in developed countries, where life expectancy has been increasing steadily after their epidemiological transition. Evaluating the general population's health is one of the specific applications proposed for health-related quality of life instruments [3].

The EQ-5D has been frequently selected for national health surveys [4-10], given its low respondent burden and its consistently proven metric properties $[6,11,12]$. However, the high percentage of individuals with the best health state in the EQ-5D $[13,14]$ has been repeatedly highlighted as a limitation, since this may reduce its capacity to discriminate within good health $[6,15,16]$, and its responsiveness in some health areas [17-19]. The traditional EQ-5D descriptive system, composed of five dimensions (mobility, self-care, usual activities, pain/discomfort, and anxiety/depression) with three levels of severity, defines 243 distinct health states [20] resulting from all the possible combinations (i.e., $3^{5}$ ). This is a very low number compared with other instruments, such as the Health Utilities Index [21] with 972,000 or the SF-6D [22] with 18,000 possible combinations.

To improve its discriminative capacity and sensitivity to change, and to reduce ceiling effects, the EuroQol Research Foundation decided to develop a new EQ-5D version increasing the number of response options from three (EQ-5D-3L) to five levels (EQ-5D-5L), resulting in 3125 health states (i.e., $5^{5}$ ). Face and content validity of the new EQ-5D-5L were demonstrated for both the English and Spanish versions through focus group research [23]. Studies performed in cancer [24, 25], hepatitis B [26], or hip arthroplasty [27] patients showed improvements for discriminative capacity [24, 26], construct validity [24-26], and responsiveness, without diminishing its reliability [25], as well as a large decrease in the percentage of individuals with the best health state.

Given the recent development of the EQ-5D-5L, there are still few head-to-head studies in general population comparing its metric properties with the traditional $3 \mathrm{~L}$ version. Studies carried out in South Korea [28], Alberta (Canada) [29], England [30] and Lombardy (Italy) [31], mainly based on national health surveys, examined both versions of EQ-5D in general population. Yet the South Korean study published in 2013 [28] was performed only in a small sample $(n=600)$, neither the Canadian [29] nor the English health surveys [30] administered both versions together, while the Italian survey did, but without comparing them. The decrease in the percentage of individuals with the best health state varied in these studies, from 42.1 to $32.3 \%$ in Alberta [29], from 56.2 to $47.6 \%$ in
England [30], from 43.9 to $38 \%$ in Lombardy [31], and from 65.7 to $61.2 \%$ in South Korea [28]. The aim of this study is a head-to-head comparison to assess to what extent expanding the number of levels in the EQ-5D from three to five has improved its distribution, discriminatory power, and validity in the general population.

\section{Methods \\ Study population}

Data used in this study came from the Catalan Health Interview Survey (CHIS), a continuous cross-sectional study carried out since 2010 in Catalonia [32], an Autonomous Community in the northeast of Spain with about seven million inhabitants. A representative sample of Catalonia's non-institutionalized population, without any age limit, is surveyed through computer-assisted personal interviews administered by an accredited team of interviewers in the respondent's home. The CHIS was approved by the Consultants' Committee of Confidential Information Management at the Catalan Health Department, according to the 2000 revision of the Helsinki Declaration.

Information collection is based on an uninterrupted random sampling strategy divided into waves with 6 months of duration. Each wave has an independent subsample of around 2500 individuals of all ages (representative of the Autonomous Community population), and a complete cycle is composed of eight waves with around 20,000 participants interviewed over 4 years (representative of the healthcare-governing districts).

\section{Study design}

The CHIS complex sampling process was designed to ensure the territorial representativeness of the sample in every wave, taking into account the distribution of the Catalan population. In a first stage, health care-governing districts were systematically selected. At a second stage, municipalities were chosen at random after stratifying by number of inhabitants. In a third stage, participants from each municipality were selected by simple random sampling from the Catalan census register, after stratifying by age and gender.

The two EQ-5D versions (3 L and $5 \mathrm{~L}$ ) were included in four waves (2nd to 5 th) of the CHIS, conducted from January 2011 to December $2012(N=9658)$. Both versions of EQ-5D were face-to-face, computer-assisted interviews, always administered in the same order: first the EQ-5D-3L and next the EQ-5D-5L, followed by the visual analogue scale. Furthermore, to assess the effect of administering the two versions of EQ-5D together, we used data from the 6th wave (the first one where EQ-5D-5L was administered alone) to compare with the 5th wave (the last one where the two EQ-5D versions were administered together).

To correct the effect of non-response, $49 \%$ of selected sampling units needed to be replaced by others with the 
same characteristics in terms of age group, sex, and neighborhood. Reasons for replacement were: refusal to participate $(25.9 \%)$, change of address $(34.7 \%)$, prolonged absence (17.8\%), inaccessible dwelling (12.6\%), wrong address $(4.0 \%)$, language skills $(0.6 \%)$, death $(1.4 \%)$, or other reasons $(3.0 \%)$.

\section{Study variables}

The EQ-5D is a generic, multi-attribute health status measure composed of a descriptive system, and a visual analogue scale (VAS) asking individuals to rate their own health from 0 to 100 (the worst and best imaginable health, respectively). The descriptive system covers five dimensions of health, and response options include three or five levels of severity according to the version. In general, the grading terms for level 1 (no problems), and 5 (extreme problems/ unable to) on the EQ-5D-5L are consistent with the extreme levels of the EQ-5D-3L, except for "confined to bed" (EQ-5D-3L) vs. "unable to walk about" (EQ-5D-5L). Label description on EQ-5D-5L is "slight" for level 2 and "severe" for level 4 (except for anxiety/depression, with "slightly" and "severely"). The Spanish value set of preferences elicited with Time Trade Off (TTO) was applied to construct the EQ-5D-3L index [33], while the EQ-5D-5L index was calculated with the crosswalk $3 \mathrm{~L}-5 \mathrm{~L}$ value set [34], derived from the original EQ-5D-3L preference weights [33]. This crosswalk $3 \mathrm{~L}-5 \mathrm{~L}$ value set was obtained using a non-parametric indirect model [34] to generate values for the $5 \mathrm{~L}$ by estimating the probabilities of being in each of the $3 \mathrm{~L}$ levels. Thus, the theoretical ranges of the EQ-5D-5L index calculated with the crosswalk value set matched exactly with the $3 \mathrm{~L}$ index: from 1 (the best health state) to -0.65 (negative values in health states valued as worse than death), where 0 is equal to death.

Sociodemographic variables recorded in the survey included gender, age, level of education, and social class. Social class was assigned according to the respondent's most recent occupation (or the head of the household's occupation in the case of those who were looking after the home), using an adapted version of the British Registrar General Social Classes: classes I and II (managerial and freelance professionals), class III (skilled non-manual occupations), class IV (skilled manual workers), and class V (non-skilled manual workers) [35].

Health indicators collected in the CHIS included general perceived health (rated as excellent, very good, good, fair or poor), limitation of daily activities due to any health problem during the previous 6 months, and a checklist of 28 common chronic conditions. Respondents were asked, "Do you suffer from or have you suffered from any of the following chronic conditions?" and had to answer "Yes" or "No" for each condition. A summary indicator was derived from the checklist, based on the number of reported chronic conditions. This discrete variable was categorized according to sample distribution into five groups: none, 1, 2, 3-4, and 5 or more chronic conditions.

\section{Statistical analysis}

The sample size of CHIS allows calculating the proportion of individuals with the best health state among those reporting stroke (the least prevalent condition among the Catalan population) for an estimated percentage of $20 \%$ with a $95 \%$ confidence interval of $+/-5$.

To restore the representativeness of the Catalan population, taking into account the complex sampling process followed (considering age, gender, and municipality), a weighting factor was applied. In addition, design-based standard errors and significance tests were estimated with the Taylor series linearization method implemented in SAS software, which account for the correlation structure among individuals induced by the stratified and clustered sampling design [36]. In order to determine the effect of the sampling in the estimations, the design effects were obtained as the ratio between two variances: the variance of the estimator under the actual sample design to that under simple random sampling of the same size.

Sample characteristics were described by calculating unweighted frequencies and weighted percentages. To evaluate the response redistribution between the classical EQ-5D and the new five level version, we first calculated weighted percentages in each level of the EQ-5D-5L after stratifying by responses to the EQ-5D-3L and, second, we assessed the inconsistencies according to the method described by Janssen et al. [37]. Briefly, from the 15 potential $3 \mathrm{~L}-5 \mathrm{~L}$ response pairs in each dimension, those skipping the adjacent categories of the $5 \mathrm{~L}$ were defined as inconsistencies. To assess validity of the response redistribution between three and five levels, we calculated the mean of the perceived health VAS in each of these 15 subgroups of potential pairs. Our hypothesis is that, except for inconsistencies, the perceived health (VAS) in subgroups of individuals selecting an EQ-5D-5L category with more severe problems is worse than in subgroups remaining in the same category of response to the EQ-5D-3L (or vice versa, better perceived health in milder problems).

The discriminatory power was examined with Shannon Indices, which were calculated for each dimension separately. The Shannon index is defined as:

$$
H^{\prime}=-\sum_{i=1}^{L} p_{i} \log _{2} p_{i}
$$

where $\mathrm{H}^{\prime}$ represents the absolute amount of informativity captured, $L$ is the number of levels, and $p_{i}=n_{i} / N$, the proportion of observations in the ith level $(i=1, \ldots, \mathrm{L}), \mathrm{n}_{\mathrm{i}}$ being the observed number of responses in level $\mathrm{i}$ and $\mathrm{N}$ the total sample size [38]. $\mathrm{H}^{\prime}$ reaches its maximum $\left(\mathrm{H}^{\prime}\right.$ max) when distribution is uniform (rectangular) and it 
equals to $\log _{2} L$. Shannon's Evenness index $\left(J^{\prime}=H^{\prime} / H^{\prime} \max \right)$ reflects the evenness (spread) of a distribution, regardless of the number of levels. The 95\% confidence intervals were calculated according to the variance of the Shannon index:

$$
\operatorname{var} H^{\prime}=\frac{\sum_{i=1}^{L} p_{i}\left(\log _{2} p_{i}\right)^{2}-\left(\sum_{i=1}^{L} p_{i} \log _{2} p_{i}\right)^{2}}{\mathrm{~N}}
$$

As previously reported [37, 39, 40], we hypothesized that the $5 \mathrm{~L}$ has more discriminatory power (larger $\mathrm{H}^{\prime}$ values) than the $3 \mathrm{~L}$ version, but lower Shannon Evenness index J', reflecting that populations need a larger spread to cover five levels than for three. Therefore, we expected the $\mathrm{H}^{\prime}$ to increase (higher absolute levels of information) and J' to stay equal or marginally decrease in the $5 \mathrm{~L}$ version.

A plot between EQ-5D-3L index ( $y$-axis) and EQ-5D-5L index ( $x$-axis) was constructed to graphically compare the distribution of both indices. We also calculated the statistics describing the distribution of EQ-5D indices: the theoretical and observed ranges, the weighted proportion and 95\% confidence intervals (95\% CI) of individuals with the best and worst health state, and parameters of central tendency and dispersion. Furthermore, a sensitivity analysis was performed to examine the consistency of results when the EQ-5D-5L index is estimated with $3 \mathrm{~L}-5 \mathrm{~L}$ crosswalk value set or with the newly developed Spanish value set obtained through a common composite method of TTO and discrete choice experiments (DCE) [41]. We calculated the statistics describing the distribution of the EQ-5D-5L index constructed with this value set in the entire sample; as well as after excluding participants with negative values in any index, because the theoretical range of this new EQ-5D-5L index $(-0.416$ to 1$)$ was not exactly coincident with the EQ-5D-3L index ( -0.653 to 1$)$ for values $<0$.

To explore the distribution of EQ-5D indices in persons with chronic conditions, the weighted proportion ( $95 \% \mathrm{CI}$ ) of individuals reporting the best possible health state (11111) in EQ-5D-3L and EQ-5D-5L within each of the 28 specific chronic conditions' groups was estimated. Furthermore, the mean $(95 \% \mathrm{CI})$ of the perceived health VAS for this subgroup of individuals reporting the best possible health state within each specific chronic condition was calculated. Since we expected a lower proportion of individuals reporting the best health state (11111) with EQ-5D-5L than with EQ-5D-3L, we hypothesized a better perceived health (VAS) when this subgroup of individuals is defined by the EQ-5D-5L.

Finally, to assess the effect of administering the EQ-5D-5L after the $3 \mathrm{~L}$ version, we compared the responses to the dimensions in the EQ-5D-5L between the samples of the 5 th $(3 \mathrm{~L}$ and $5 \mathrm{~L}$ versions administered together) and 6th waves (EQ-5D-5L administered alone) using a Chi-squared test.

\section{Results}

Of the 9658 participants in the CHIS between January 2011 and December 2012, 7554 individuals aged 18 to 102 years old were analyzed after excluding 2104 people younger than 18. Mean age of participants was 47.1 (SD $=18.9$ ), and $50.9 \%$ were female (Table 1 ). More than half had completed secondary studies, $40 \%$ belonged to social class IV, and $48.5 \%$ suffered three or more chronic conditions. Only $15 \%$ of the individuals reported some limitation of activities in the previous 6 months, and 34.3\% claimed to have either excellent or very good perceived health (Table 1).

Cross tabulations of responses to both EQ-5D versions (Table 2) showed that most of the participants reporting no problems in the $3 \mathrm{~L}$ version remained at Level 1 in the $5 \mathrm{~L}$ version, and only $1-2 \%$ moved to slight problems. In contrast, a large proportion of individuals reporting extreme problems in the $3 \mathrm{~L}$ version had moved to severe problems (Level 4 ) in the $5 \mathrm{~L}$ version. This proportion was particularly marked for pain/discomfort (75.5\%) and anxiety/depression (66.4\%). Grey cells show the pairs previously defined as inconsistencies. The number of inconsistencies was highest in the pain/discomfort domain $(n=189 ; 2.4 \%)$ and lowest in the self-care one $(n=54 ; 0.6 \%)$. The average proportion of inconsistencies by dimension was $0.9 \%$.

Regarding the validity of the redistribution between three and five levels, the mean of the perceived health VAS was over 75 in the subgroup of individuals reporting no problems in both versions for all dimensions (range 75.4-79.7). Confirming the hypothesis established a priori, the perceived health VAS mean in subgroups of individuals selecting an EQ-5D-5L category of more severe problems is worse than in those remaining in the same category as in the EQ-5D-3L. Similarly, those moving to milder problems in the EQ-5D-5L presented better perceived health. For example, in the last row of Table 2 (extremely anxious or depressed in the EQ-5D-3L), the $66.4 \%$ who moved to a milder level in the $5 \mathrm{~L}$ (severe problems) presented better perceived health than those who remained at the extreme level (11.5\%): mean VAS of 41.7 vs. 29.5 .

Figure 1 shows Shannon indices of EQ-5D-3L and EQ-5D-5L. The maximum information captured by the system (H'max in light bars), and also the absolute informativity ( $\mathrm{H}^{\prime}$ in dark bars) is higher in $5 \mathrm{~L}$ than in $3 \mathrm{~L}$ version. However, when $\mathrm{H}^{\prime}$ is compared with the $\mathrm{H}^{\prime} \max$, the relative information area captured $\left(J^{\prime}\right)$ is significantly lower in EQ-5D-5L than in $3 \mathrm{~L}$ for all dimensions except self-care. This difference is especially marked in pain/ discomfort ( ${ }^{\prime}=0.59$ vs. 0.68 ) and anxiety/depression (J' $=0.42$ vs. 0.50 ).

Figure 2 shows the plot between EQ-5D-3L and EQ-5D-5L indices. The cloud of points and the biggest clusters of individuals were concentrated around the perfect agreement diagonal, indicating a high correlation 
Table 1 Sample characteristics of the Catalan Health Interview Survey (2011-2012)

\begin{tabular}{|c|c|c|c|c|}
\hline & n (\%) Unweighted & n (\%) Weighted & $\mathrm{SE}^{\mathrm{a}}$ & Design effect \\
\hline \multicolumn{5}{|l|}{ Gender } \\
\hline Male & 3791 (50.2\%) & 3877 (49.1\%) & 0.20 & 0.19 \\
\hline Female & 3763 (49.8\%) & 4014 (50.9\%) & 0.20 & 0.19 \\
\hline \multicolumn{5}{|l|}{ Age group } \\
\hline 18-44 years & 3527 (46.7\%) & 3801 (48.2\%) & 0.45 & 0.62 \\
\hline $45-64$ years & 2259 (29.9\%) & 2436 (30.9\%) & 0.76 & 2.08 \\
\hline $65-74$ years & $753(10.0 \%)$ & 784 (9.9\%) & 0.33 & 0.92 \\
\hline 75 years and over & 1015 (13.4\%) & $870(11.0 \%)$ & 0.29 & 0.53 \\
\hline \multicolumn{5}{|l|}{ Studies level } \\
\hline Primary or less & 2015 (26.7\%) & 1993 (25.3\%) & 2.19 & 18.52 \\
\hline Secondary & $4179(55.4 \%)$ & 4345 (55.1\%) & 1.65 & 8.31 \\
\hline University or more & $1356(18.0 \%)$ & $1548(19.6 \%)$ & 3.44 & 60.70 \\
\hline \multicolumn{5}{|l|}{ Social class } \\
\hline I-II (managerial and free-lance professionals) & $1312(18.0 \%)$ & $1485(19.5 \%)$ & 2.83 & 40.90 \\
\hline III (skilled non-manual occupations) & $2226(30.6 \%)$ & $2390(31.3 \%)$ & 2.36 & 19.84 \\
\hline IV (skilled manual workers) & 3067 (42.2\%) & $3052(40.0 \%)$ & 4.71 & 68.95 \\
\hline V (non-skilled manual workers) & $671(9.2 \%)$ & $701(9.2 \%)$ & 0.59 & 3.18 \\
\hline \multicolumn{5}{|l|}{ Perceived health } \\
\hline Excellent & $564(7.5 \%)$ & $636(8.1 \%)$ & 0.82 & 7.41 \\
\hline Very good & $1895(25.1 \%)$ & $2067(26.2 \%)$ & 1.64 & 10.84 \\
\hline Good & $3388(44.9 \%)$ & $3452(43.7 \%)$ & 2.08 & 13.25 \\
\hline Fair & $1356(18.0 \%)$ & $1374(17.4 \%)$ & 0.48 & 1.20 \\
\hline Poor & $351(4.7 \%)$ & $362(4.6 \%)$ & 0.41 & 2.82 \\
\hline \multicolumn{5}{|l|}{ Activity limitation } \\
\hline Yes, seriously affected & $398(5.3 \%)$ & $397(5.0 \%)$ & 0.33 & 1.60 \\
\hline Yes, limited but not seriously & $762(10.1 \%)$ & $786(10.0 \%)$ & 0.63 & 3.33 \\
\hline No & $6394(84.6 \%)$ & $6708(85.0 \%)$ & 0.85 & 4.19 \\
\hline \multicolumn{5}{|l|}{ Number of chronic physical conditions } \\
\hline None & $1690(22.4 \%)$ & $1783(22.6 \%)$ & 1.60 & 11.21 \\
\hline 1 condition & $1183(15.7 \%)$ & $1256(15.9 \%)$ & 0.55 & 1.75 \\
\hline 2 conditions & $981(13.0 \%)$ & 1017 (12.9\%) & 0.50 & 1.66 \\
\hline 3 or 4 conditions & $1432(19.0 \%)$ & $1526(19.3 \%)$ & 0.47 & 1.07 \\
\hline 5 or more conditions & $2268(30.0 \%)$ & $2308(29.2 \%)$ & 1.36 & 6.68 \\
\hline VAS (mean, SD) & 7554 & $73.19(19.21)$ & 0.42 & 5.21 \\
\hline
\end{tabular}

${ }^{\mathrm{a}}$ Standard error was estimated by the Taylor series method

between both indices. A slight deviation to higher values with the EQ-5D-5L than the EQ-5D-3L is also observable.

Table 3 shows the statistics describing distribution of the EQ-5D indices. Ranges observed in our sample matched exactly with the theoretical ranges (from -0.65 to 1). The proportion of individuals with the worst health state was negligible $(<0.15 \%)$, while the proportion with the best health state was $61.8 \%$ with EQ-5D-3L and $60.8 \%$ with EQ-5D-5L. Means (SD) were 0.87 (0.25) and 0.89
(0.22) for EQ-5D-3L and EQ-5D-5L. Sensitivity analysis performed with the EQ-5D-5L index constructed with the newly developed Spanish value set [41] (see Additional file 1) showed consistent results: mean $0.90(\mathrm{SD}=$ $0.19)$ in the entire sample, and mean $0.92(\mathrm{SD}=0.14)$ after excluding the 249 subjects with negative values. Differences between EQ-5D-3L and EQ-5D-5L indices remained quite stable regardless the value set used.

Figure 3 shows results by each specific chronic condition: the proportion of individuals with the best 
Table 2 Comparison between EQ-5D-5L and EQ-5D-3L responses, and mean of perceived health VAS

\begin{tabular}{|c|c|c|c|c|c|}
\hline \multirow[b]{2}{*}{ EQ-5D-3L } & \multicolumn{5}{|l|}{ EQ-5D-5L } \\
\hline & $\begin{array}{c}\text { No } \\
\text { problems } \\
1\end{array}$ & $\begin{array}{c}\text { Slight } \\
\text { problems } \\
2\end{array}$ & $\begin{array}{c}\text { Moderate } \\
\text { problems } \\
3\end{array}$ & $\begin{array}{c}\text { Severe } \\
\text { problems } \\
4\end{array}$ & $\begin{array}{c}\text { Unable/ } \\
\text { extreme } \\
5\end{array}$ \\
\hline \multicolumn{6}{|l|}{ Mobility } \\
\hline $\begin{array}{l}\text { No problems in walking about } \\
(n=6390)\end{array}$ & $\begin{array}{l}6287(98.6 \%) \\
{[77.4]}\end{array}$ & $\begin{array}{l}86(1.2 \%) \\
{[58.5]}\end{array}$ & $\begin{array}{l}16(0.2 \%) \\
{[53.5]}\end{array}$ & $\begin{array}{l}1(0.0 \%) \\
{[15.0]}\end{array}$ & $0(0.0 \%)$ \\
\hline $\begin{array}{l}\text { Some problems in walking about } \\
(n=1104)\end{array}$ & $\begin{array}{l}36(3.2 \%) \\
{[60.7]}\end{array}$ & $\begin{array}{l}392(34.8 \%) \\
{[57.0]}\end{array}$ & $\begin{array}{l}436(41.1 \%) \\
{[48.9]}\end{array}$ & $\begin{array}{l}221(19.8 \%) \\
{[38.2]}\end{array}$ & $\begin{array}{l}19(1.1 \%) \\
{[52.2]}\end{array}$ \\
\hline $\begin{array}{l}\text { Confined to bed } \\
(n=60)\end{array}$ & $\begin{array}{l}3(4.4 \%) \\
{[74.5]}\end{array}$ & $\begin{array}{l}1(0.2 \%) \\
{[40.0]}\end{array}$ & $\begin{array}{l}3(7.9 \%) \\
{[37.3]}\end{array}$ & $\begin{array}{l}15(26.5 \%) \\
{[35.2]}\end{array}$ & $\begin{array}{l}38(60.9 \%) \\
{[35.5]}\end{array}$ \\
\hline \multicolumn{6}{|l|}{ Self-care } \\
\hline $\begin{array}{l}\text { No problems with self-care } \\
(n=7057)\end{array}$ & $\begin{array}{l}6956(98.6 \%) \\
{[75.4]}\end{array}$ & $\begin{array}{l}88(1.2 \%) \\
{[46.8]}\end{array}$ & $\begin{array}{l}12(0.2 \%) \\
{[32.5]}\end{array}$ & $\begin{array}{l}1(0.0 \%) \\
{[40.0]}\end{array}$ & $(0.0 \%)$ \\
\hline $\begin{array}{l}\text { Some problems washing or dressing myself } \\
(n=345)\end{array}$ & $\begin{array}{l}27(6.3 \%) \\
{[61.8]}\end{array}$ & $\begin{array}{l}109(29.1 \%) \\
{[49.9]}\end{array}$ & $\begin{array}{l}154(48.9 \%) \\
{[43.7]}\end{array}$ & $\begin{array}{l}51(14.9 \%) \\
{[30.6]}\end{array}$ & $\begin{array}{l}4(0.8 \%) \\
{[24.9]}\end{array}$ \\
\hline $\begin{array}{l}\text { Unable to wash or dress myself } \\
(n=152)\end{array}$ & $\begin{array}{l}2(1.5 \%) \\
{[76.9]}\end{array}$ & $\begin{array}{l}3(1.7 \%) \\
{[52.3]}\end{array}$ & $\begin{array}{l}5(3.6 \%) \\
{[55.4]}\end{array}$ & $\begin{array}{l}29(18.4 \%) \\
{[44.7]}\end{array}$ & $\begin{array}{l}113(74.9 \%) \\
{[36.5]}\end{array}$ \\
\hline \multicolumn{6}{|l|}{ Usual activities } \\
\hline $\begin{array}{l}\text { No problems with performing my usual activities } \\
(n=6677)\end{array}$ & $\begin{array}{l}6526(97.8 \%) \\
{[77.0]}\end{array}$ & $\begin{array}{l}105(1.6 \%) \\
{[58.2]}\end{array}$ & $\begin{array}{l}37(0.5 \%) \\
{[56.5]}\end{array}$ & $\begin{array}{l}8(0.1 \%) \\
{[36.3]}\end{array}$ & $\begin{array}{l}1(0.0 \%) \\
{[70.0]}\end{array}$ \\
\hline $\begin{array}{l}\text { Some problems with performing } \\
\text { my usual activities }(n=600)\end{array}$ & $\begin{array}{l}31(4.3 \%) \\
{[59.0]}\end{array}$ & $\begin{array}{l}197(31.3 \%) \\
{[53.8]}\end{array}$ & $\begin{array}{l}269(46.3 \%) \\
{[46.0]}\end{array}$ & $\begin{array}{l}92(16.3 \%) \\
{[40.0]}\end{array}$ & $\begin{array}{l}11(1.7 \%) \\
{[47.1]}\end{array}$ \\
\hline $\begin{array}{l}\text { Unable to perform my usual activities } \\
(n=277)\end{array}$ & $\begin{array}{l}1(0.6 \%) \\
{[70.0]}\end{array}$ & $\begin{array}{l}2(0.5 \%) \\
{[69.1]}\end{array}$ & $\begin{array}{l}20(7.7 \%) \\
{[48.8]}\end{array}$ & $\begin{array}{l}81(30.0 \%) \\
{[42.2]}\end{array}$ & $\begin{array}{l}173(61.3 \%) \\
{[35.0]}\end{array}$ \\
\hline \multicolumn{6}{|l|}{ Pain/discomfort } \\
\hline $\begin{array}{l}\text { No pain or discomfort } \\
(n=5275)\end{array}$ & $\begin{array}{l}5124(97.3 \%) \\
{[79.7]}\end{array}$ & $\begin{array}{l}113(2.0 \%) \\
{[68.1]}\end{array}$ & $\begin{array}{l}34(0.6 \%) \\
{[65.5]}\end{array}$ & $\begin{array}{l}4(0.1 \%) \\
{[65.9]}\end{array}$ & $0(0 \%)$ \\
\hline $\begin{array}{l}\text { Moderate pain of discomfort } \\
(n=1846)\end{array}$ & $\begin{array}{l}73(3.7 \%) \\
{[68.7]}\end{array}$ & $\begin{array}{l}790(41.9 \%) \\
{[67.6]}\end{array}$ & $\begin{array}{l}875(47.9 \%) \\
{[59.4]}\end{array}$ & $\begin{array}{l}107(6.6 \%) \\
{[49.4]}\end{array}$ & $\begin{array}{l}1(0.0 \%) \\
{[40.0]}\end{array}$ \\
\hline $\begin{array}{l}\text { Extreme pain or discomfort } \\
(n=433)\end{array}$ & $\begin{array}{l}0(0 \%) \\
-\end{array}$ & $\begin{array}{l}7(1.8 \%) \\
{[55.8]}\end{array}$ & $\begin{array}{l}70(15.7 \%) \\
{[47.9]}\end{array}$ & $\begin{array}{l}324(75.5 \%) \\
{[40.1]}\end{array}$ & $\begin{array}{l}32(7.0 \%) \\
{[34.2]}\end{array}$ \\
\hline \multicolumn{6}{|l|}{ Anxiety/depression } \\
\hline $\begin{array}{l}\text { Not anxious or depressed } \\
(n=6226)\end{array}$ & $\begin{array}{l}6098(98.1 \%) \\
{[77.4]}\end{array}$ & $\begin{array}{l}100(1.5 \%) \\
{[61.0]}\end{array}$ & $\begin{array}{l}21(0.3 \%) \\
{[65.8]}\end{array}$ & $\begin{array}{l}6(0.0 \%) \\
{[43.9]}\end{array}$ & $\begin{array}{l}1(0.0 \%) \\
{[50.0]}\end{array}$ \\
\hline $\begin{array}{l}\text { Moderately anxious or depressed } \\
(n=1111)\end{array}$ & $\begin{array}{l}52(4.5 \%) \\
{[58.0]}\end{array}$ & $\begin{array}{l}526(47.0 \%) \\
{[62.1]}\end{array}$ & $\begin{array}{l}474(43.6 \%) \\
{[54.8]}\end{array}$ & $\begin{array}{l}56(4.6 \%) \\
{[46.1]}\end{array}$ & $\begin{array}{l}3(0.3 \%) \\
{[22.3]}\end{array}$ \\
\hline $\begin{array}{l}\text { Extremely anxious or depressed } \\
(n=217)\end{array}$ & $\begin{array}{l}3(1.5 \%) \\
{[49.6]}\end{array}$ & $\begin{array}{l}6(2.4 \%) \\
{[51.5]}\end{array}$ & $\begin{array}{l}37(18.2 \%) \\
{[46.5]}\end{array}$ & $\begin{array}{l}147(66.4 \%) \\
{[41.7]}\end{array}$ & $\begin{array}{l}24(11.5 \%) \\
{[29.5]}\end{array}$ \\
\hline
\end{tabular}

$\mathrm{N}$ unweighted, (weighted \% by response to EQ-5D-3L) and [mean VAS]. Inconsistencies are marked in bold

health state (11111) in the EQ-5D-3L (blue bars) and EQ-5D-5L (green bars), and also the mean (95\% CI) of perceived health VAS in subgroups with and without the best health state. In both indices, chronic allergies presented the highest proportion of subjects with the best health state (50.6 and 50.1\%), and urinary incontinence the lowest (13.1 and $12.0 \%)$. Regardless of the index used, the proportion of individuals with the best health state was $\leq 30 \%$ in half of the chronic conditions from the checklist (cervical pain, tumors, arthrosis, arthritis or rheumatism, peptic ulcer, poor circulation, other health illnesses, cataracts, myocardial infarction, chronic constipation, anxiety or depression, other mental disorders, stroke, osteoporosis, and urinary incontinence). The mean of the VAS for the subgroup with the best possible health state defined by EQ-5D-3L and EQ-5D-5L (in dark blue and green lines, respectively) was over 70 within all specific chronic condition groups, ranging 71.3-79.8 and 72.6-81.3, respectively. Perceived health VAS means in the subgroups defined by the EQ-5D-3L were very similar to those obtained in the subgroups defined by EQ-5D-5L. For the subgroup with some health problem (not 11111), mean of VAS was always lower than 60 (light blue and green lines). 


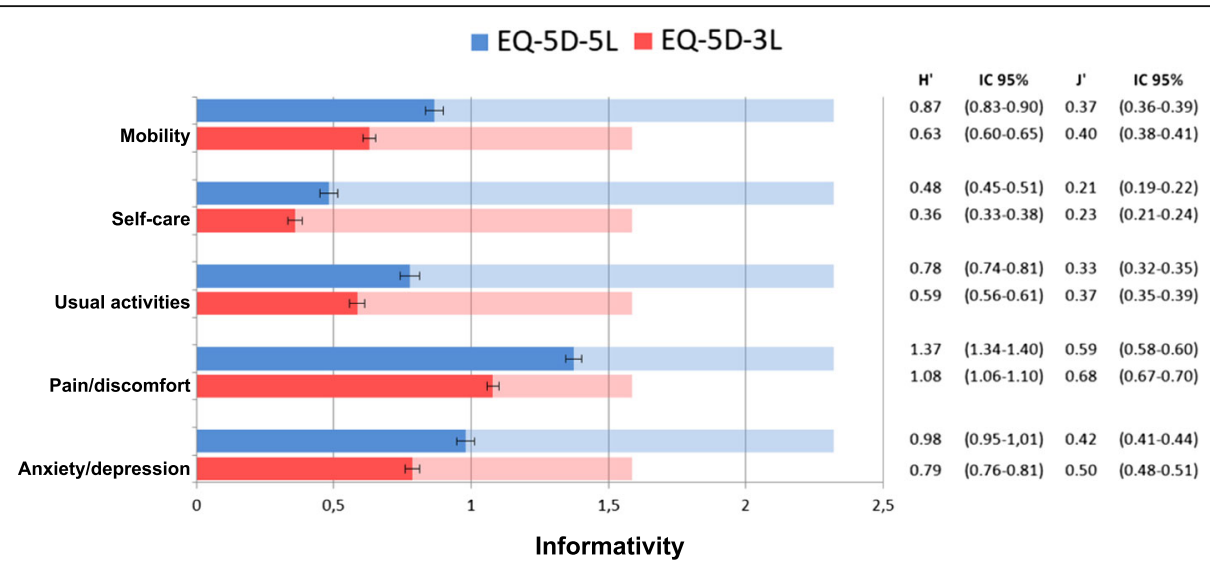

Fig. 1 Discriminatory power measured by Shannon Indices for $3 L$ and $5 L$ version. Footnote: Absolute Informativity $\left(H^{\prime}\right)$ represented by dark bars and Maximum Absolute Informativity ( $H^{\prime}$ max) represented by light bars. The Relative Informativity $\left(J^{\prime}\right)$ is the proportion of $H^{\prime} / H^{\prime}$ max

\section{Discussion}

This head-to-head comparison of EQ-5D-5L with EQ-5D-3L in the general population of Catalonia shows that redistribution of levels is mostly in individuals reporting extreme problems on the EQ-5D-3L, which moved to level 4 on the EQ-5D-5L, but not for those reporting no problem, who remained at the top. This explains the very small reduction in the percentage of individuals with the best health state, from $61.8 \%$ with EQ-5D-3L to $60.8 \%$ with EQ-5D-5L, and the increment of the index mean (from 0.87 to 0.89 ) in our sample.

One of the original contributions of this study is that, as far as we are aware, this is the first time that distribution and validity of the EQ-5D-5L have been compared head-to-head to those of the EQ-5D-3L in a health survey on general population.
In the Lombardy study both versions were also administered, but they were not compared since the publication was focused on reference norms [31].

Our study has some limitations. Firstly, the two versions of the EQ-5D were always administered in the same order: first the $3 \mathrm{~L}$ and then the $5 \mathrm{~L}$. This proximity might have affected the EQ-5D-5L, which was always administered second. However, the comparison with the 6th wave (see Additional file 2), where only the EQ-5D-5L was administered, showed no differences in EQ-5D-5L dimensions, except for pain/discomfort (72.4\% versus $67.6 \%$ of individuals reporting no problem, $p=0.003)$. This finding indicates that the fact of administering the two versions together did not modify the response to the EQ-5D-5L when administered alone (as in the 6th wave). Furthermore, results from the 2011 National Health Survey of

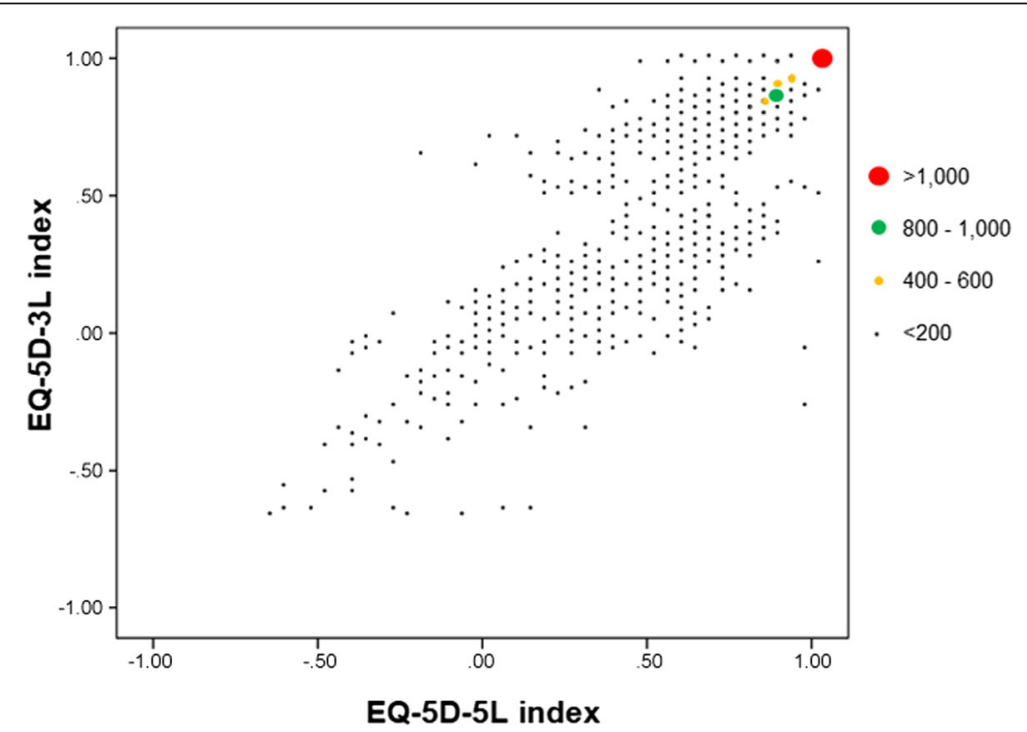

Fig. 2 Plot between EQ-5D-3L and EQ-5D-5L indices. Footnote: The EQ-5D-3L index was calculated with the conventional Time Trade Off preference values from the Spanish general population [33]; and the EQ-5D-5L index was calculated with the $3 \mathrm{~L}-5 \mathrm{~L}$ crosswalk from Spain [34] 
Table 3 Distribution of the EQ-5D-3L and EQ-5D-5L indices (total sample and positive values subsample ${ }^{a}$ )

\begin{tabular}{lll}
\hline & EQ-5D-3L & EQ-5D-5L \\
Total sample & $N=7554$ & $N=7554$ \\
\hline Theoretical range & $-0.653,1$ & $-0.654,1$ \\
Observed range & $-0.653,1$ & $-0.654,1$ \\
$\%$ with worst health state & $0.14 \%$ & $0.03 \%$ \\
(95\% Cl) & $(0.04,0.24)$ & $(0,0.08)$ \\
$\%$ with best health & $61.82 \%$ & $60.82 \%$ \\
(95\% CI) & $(59.38 .64 .26)$ & $(58.36,63.28)$ \\
Mean, SD & $0.87, \mathrm{SD}=0.25$ & $0.89, \mathrm{SD}=0.22$ \\
(95\% CI) & $(0.86,0.88)$ & $(0.88,0.90)$ \\
Median [IQR] & 0.93 & 0.94 \\
& {$[0.87,0.96]$} & {$[0.88,0.97]$} \\
\hline
\end{tabular}

${ }^{\mathrm{a}}$ After excluding participants with negative values in any index The EQ-5D-3L index was calculated with the conventional Time Trade Off preference values from the Spanish general population [33]; and the EQ-5D-5L index was calculated with the $3 \mathrm{~L}-5 \mathrm{~L}$ crosswalk from Spain [34]

Spain (62.4\% of individuals with the best health state) where only the $5 \mathrm{~L}$ version was administered [42] also support our EQ-5D-5 L findings in Catalonia. Secondly, an interviewer bias may have played a role, and this could be differential for those dimensions where the wording of the response option had been modified in the EQ-5D-5L. For example, in the extreme of mobility ("confined to bed" for the EQ-5D-3L versus "unable to walk about" for the EQ-5D-5L), interviewers might have attenuated the severity. Finally, our sample is only representative of Catalonia. However, given the similarities in national indicators such as life expectancy or healthy life years in the general population of Catalonia, Spain, and other European regions [43], it is likely that our results will be generalizable to similar developed countries.
The small reduction observed in the percentage of individuals with the best health state, from $61.8 \%$ with EQ-5D-3L to $60.8 \%$ with EQ-5D-5L, is due to the negligible movement from level 1 out of 3 ("no problem") to level 2 out of 5 ("slight problems") in all dimensions. This absolute reduction of $1 \%$ (relative reduction of $1.6 \%$ ) in the proportion of individuals with the best health state was lower than that reported in the population of South Korea and Lombardy (absolute reductions of 4.5 , and $5.9 \%$, respectively) $[28,31]$. The Canadian and English studies [29, 30] reported greater differences of 9.8 and $8.6 \%$; but as previously remarked, they were not head-to-head comparisons, so this could be explained by other reasons related to the study design, rather than to differences between EQ-5D versions.

This is the first time that redistribution of a large proportion of individuals from extreme to severe problems has been reported in a general population. Depending on the dimension, between 18.3 and $75.7 \%$ of individuals reporting extreme problems in the $3 \mathrm{~L}$ version moved to level 4 (severe problems) in the $5 \mathrm{~L}$ one. The better perceived health in this latter subgroup (VAS mean over 40 in most domains), compared with the subgroup remaining in extreme problems (VAS mean ranging from 29.5 in anxiety/depression to 36.5 in self-care), supports the validity of the redistribution phenomenon observed in the side of the EQ-5D descriptive system indicating poor health. This may indicate that the EQ-5D-5L can measure the health state of individuals with severe (but not extreme) health problems in the Catalan general population better than the EQ-5D-3L. This partly explains why the index mean of the new version was higher (0.89) than that obtained with the traditional version with three levels $(0.87)$.

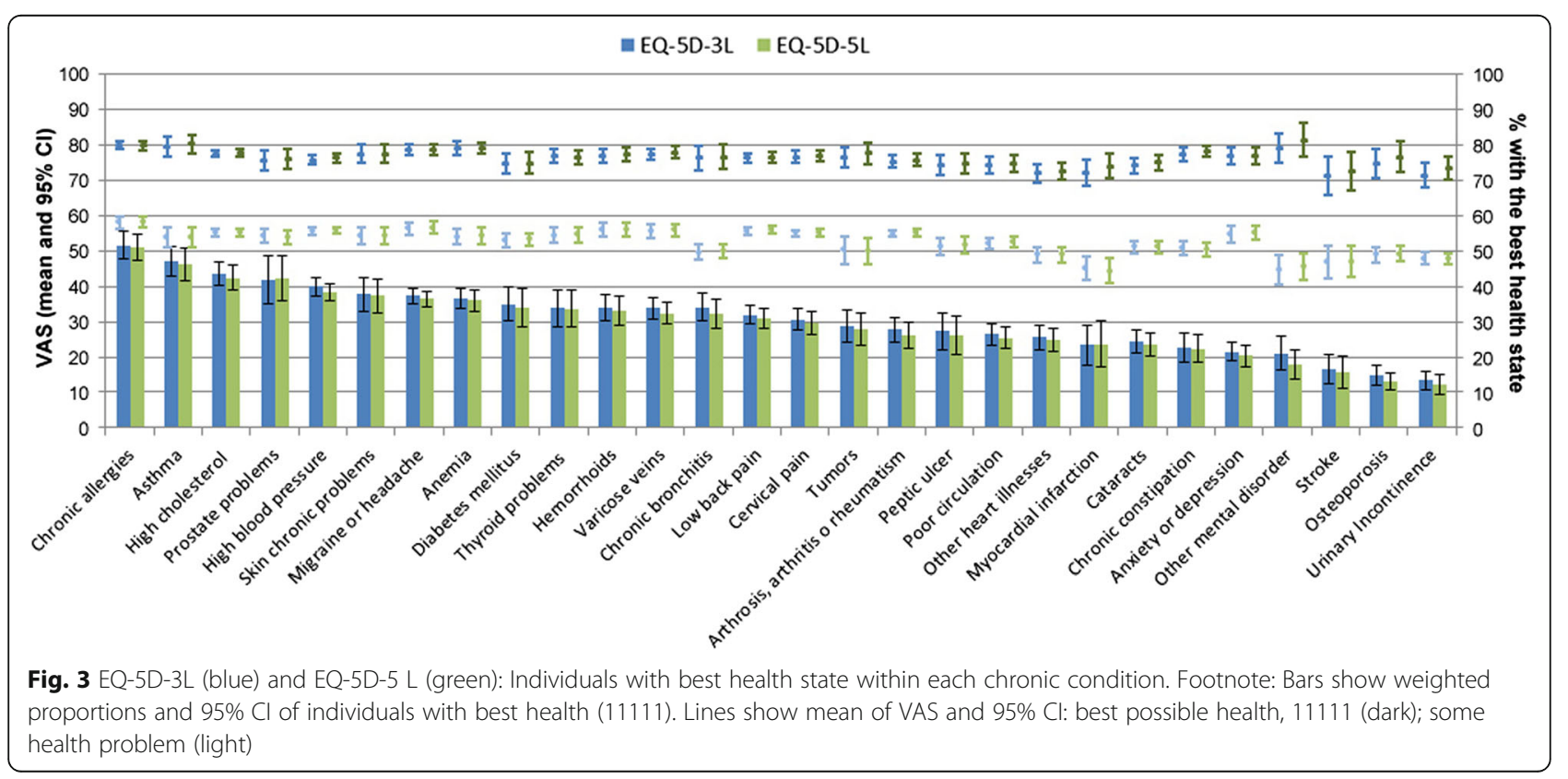


Due to its small sample size $(N=600)$, the South Korean study could not observe this redistribution because there were too few participants on level 3 of EQ-5D-3L (0-6 individuals) [28], while the Italian study did not assess the redistribution [31]. It is important to highlight the low average proportion of inconsistencies between both EQ-5D versions in our study (0.9\%), which was comparable to the South Korean general population (1.1\%) [28], and lower than that reported among patients with cancer (3.5\%) [25] or with chronic conditions (2.9\%) [39].

As expected, extending the EQ-5D descriptive system from three to five levels resulted in significantly higher absolute, but slightly lower relative (evenness) discriminatory power. J' values have also been found slightly lower in some dimensions of EQ-5D-5L in previous comparative studies $[37,39,40]$. The absolute and relative informativity of both EQ-5D versions in our study (0.36-1.37 and $0.21-0.68$, respectively) were similar to those reported by Pattanaphesaj et al. [40] $(0.12-1.40$ and $0.08-$ $0.63)$, but lower than those observed in others [37, 39]. The relatively good health of people from the Catalan general population could partly explain the lower absolute informativity observed in our study.

The difference observed between EQ-5D-3L and EQ-5D-5L indices for medians and means (SD) merits a comment. The EQ-5D-5L index presented a slightly higher median and mean, but a reduced SD compared with the EQ-5D-3L index. Since the crosswalk $3 \mathrm{~L}-5 \mathrm{~L}$ value set applied to calculate the EQ-5D-5L index had been derived from that originally developed for the $3 \mathrm{~L}$ version, these differences may be mainly explained by the increment in the number of levels. For this reason, it is recommendable that national health surveys using the EQ-5D-3L that decide to replace it with the EQ-5D-5L maintain both versions, at least in a random subsample, for a temporary period. Results in these subsamples will allow anchoring results of the two versions, in order to take into account the version effect and correctly monitor the evolution of health along time. Otherwise, changes observed when monitoring populations could be mistakenly attributed to health worsening/improvement instead of measurement differences between versions.

The most prevalent chronic conditions in this sample were low back pain (30\%), arthrosis, arthritis or rheumatism (27.8\%), and high blood pressure (25.6\%), while stroke was the least prevalent with a rate of $2.4 \%$ (data not shown). Contrarily to the a priori hypothesis, both EQ-5D versions had an almost identical validity measuring health in individuals who self-reported chronic conditions and with the best health state. This unexpected result is probably explained by the very similar percentage of individuals with the best health state within each specific chronic condition, regardless of the EQ-5D version. Although larger reductions in this percentage were reported in studies of specific conditions such as hepatitis B (21.6 to 16.7\%) [26] and surgery patients (30 to $18 \%$ ) [27], the decline observed in the groups with specific chronic conditions within our sample was $\leq 3 \%$ in all cases. This difference could be due to self-reporting instead of clinical diagnoses.

\section{Conclusions}

The increase of levels provided by the EQ-5D-5L contributed to the validity and discriminatory power of this new version. The group of individuals with poor health was redistributed into different severity levels, while in the EQ-5D-3L they were stuck in the category of extreme problems. The proportion of individuals with the best health state is still very high in the EQ-5D-5L. Nonetheless, results of perceived health VAS support validity of the observed redistribution. Furthermore, consistency between both EQ-5D versions and with results from the 2011 Spanish National Health Survey enhance the reliability of responses from this subset of general population in good health.

Our findings support the validity and discriminatory power of the new EQ-5D-5L for health measurement of the general population. However, it would be advisable to maintain both versions in parallel for a temporary period when introducing the new EQ-5D-5L to a national health survey currently using the EQ-5D-3L version in order to establish an anchor.

\section{Additional files}

Additional file 1: Sensitivity analysis performed with the newly developed Spanish value set obtained through a common composite method of Time Trade Off (TTO) and discrete choice experiments (DCE): Distribution of the EQ-5D-3L and EQ-5D-5L indices (total sample and positive values subsample). (DOCX $15 \mathrm{~kb}$ )

Additional file 2: EQ-5D-5L comparison between 5th and 6th waves to assess effect of administering it after EQ-5D-3L. (DOCX $19 \mathrm{~kb}$ )

\section{Abbreviations \\ CHIS: Catalan Health Interview Survey; IQR: Interquartile range; SD: Standard deviation; TTO: Time Trade Off}

\section{Acknowledgements}

We acknowledge Aurea Martin for helping us in the English editing process and supervision of this manuscript. We would also like to thank Karina Mayoral for her editing and revision of this article.

\section{Funding}

This work was supported by grants from Instituto de Salud Carlos III FEDER, (PI12/00772 and PI16/00130), Contract of training in research, ISCIII FIS Río Hortega CM15/00167, and DIUE of Generalitat de Catalunya (2014 SGR 748 and 2017 SGR 452).

\section{Availability of data and materials}

The Catalan Health Interview Survey is an official statistic in the current Statistical Plan of Catalonia which carries a guarantee of data confidentiality (Catalonia statistic law 23/1998, 30th December). The anonymous microdata of the Catalan Health Interview Survey can be requested for purposes of scientific research (contact e-mail: dgprs.salut@gencat.cat). 


\section{Transparency}

The lead authors (MMP and MF) affirm that this manuscript is an honest, accurate, and transparent account of the study being reported; that no important aspects of the study have been omitted; and that any discrepancies from the study as planned have been explained.

\section{Authors' contributions}

MMP analysed and interpreted the data, drafted and critically revised the manuscript and did the statistical analysis. AP analyzed and interpreted the data, and did the statistical analysis. MA interpreted the data, and critically revised the manuscript. OG conceived and designed the study, interpreted the data, and critically revised the manuscript. GV analyzed and interpreted the data, and critically revised the manuscript. CGF interpreted the data, and critically revised the manuscript. YP interpreted the data, and critically revised the manuscript. RT interpreted the data and critically revised the manuscript. AM interpreted the data and critically revised the manuscript. OGC interpreted the data and critically revised the manuscript. JC interpreted the data and critically revised the manuscript. LR interpreted the data and critically revised the manuscript. JA provided supervision, conceived and designed the study, interpreted the data, drafting, and critically revised the manuscript. MF obtained funding, provided supervision, conceived and designed the study, interpreted the data, drafting, and critically revised the manuscript. All authors read and approved the final manuscript.

\section{Ethics approval and consent to participate}

The Catalan Health interview survey was approved by the Consultants' Committee of Confidential Information Management (CATIC) from the Catalan Health Department, according to the 2000 revision of the Helsinki Declaration.

\section{Consent for publication}

Not applicable.

\section{Competing interests}

The authors declare that they have no competing interests.

\section{Publisher's Note}

Springer Nature remains neutral with regard to jurisdictional claims in published maps and institutional affiliations.

\section{Author details}

'IMIM (Hospital del Mar Medical Research Institute), Health Services Research Group, Doctor Aiguader, 88, 08003 Barcelona, Spain. ${ }^{2}$ CIBER en Epidemiología y Salud Pública (CIBERESP), Madrid, Spain. ${ }^{3}$ Universitat Autonoma de Barcelona (UAB), Barcelona, Spain. ${ }^{4}$ Universidad Pompeu Fabra, Barcelona, Spain. ${ }^{5}$ Direcció General de Planificació en Salut. Departament de Salut de la Generalitat de Catalunya, Barcelona, Spain. ' $P$ Public University of Navarra, Pamplona, Spain. ${ }^{7}$ Agency for Healthcare Quality and Assessment of Catalonia (AQUAS), Barcelona, Spain.

Received: 28 February 2017 Accepted: 13 July 2018

Published online: 16 August 2018

\section{References}

1. Black N. Patient reported outcome measures could help transform healthcare. BMJ. 2013;346:1167.

2. Garratt A, Schmidt L, Mackintosh A, Fitzpatrick R. Quality of life measurement: bibliographic study of patient assessed health outcome measures. BMJ. 2002:324:1417.

3. Aaronson N, Alonso J, Burnam A, Lohr KN, Patrick DL, Perrin E, et al. Assessing health status and quality-of-life instruments: attributes and review criteria. Qual Life Res. 2002;11:193-205.

4. Luo N, Johnson JA, Shaw JW, Feeny D, Coons SJ. Self-reported health status of the general adult U.S. population as assessed by the EQ-5D and health utilities index. Med Care. 2005;43:1078-86.

5. Kind P, Dolan P, Gudex C, Williams A. Variations in population health status: results from a United Kingdom national questionnaire survey. BMJ. 1998;316:736-41.

6. Johnson JA, Pickard AS. Comparison of the EQ-5D and SF-12 health surveys in a general population survey in Alberta, Canada. Med Care. 2000;38:115-21.

7. Devlin N, Hansen P. Herbison P. Variations in self-reported health status: results from a New Zealand survey. N Z Med J. 2000;113:517-20.
8. Burstrom $\mathrm{K}$, Johannesson $\mathrm{M}$, Rehnberg $\mathrm{C}$. Deteriorating health status in Stockholm 1998-2002: results from repeated population surveys using the EQ-5D. Qual Life Res. 2007;16:1547-53.

9. Saarni Sl, Harkanen T, Sintonen H, Suvisaari J, Koskinen S, Aromaa A, et al. The impact of 29 chronic conditions on health-related quality of life: a general population survey in Finland using 15D and EQ-5D. Qual Life Res. 2006;15:1403-14.

10. Shin $\mathrm{H}$, Kim D. Health inequality measurement in Korea using EuroQol-5 dimension valuation weights. J Prev Med Public Health. 2008;41:165-72.

11. Cunillera O, Tresserras R, Rajmil L, Vilagut G, Brugulat P, Herdman M, et al. Discriminative capacity of the EQ-5D, SF-6D, and SF-12 as measures of health status in population health survey. Qual Life Res. 2010;19:853-64.

12. Johnson JA, Coons SJ. Comparison of the EQ-5D and SF-12 in an adult US sample. Qual Life Res. 1998;7:155-66.

13. Brazier J, Roberts J, Tsuchiya A, Busschbach J. A comparison of the EQ-5D and SF-6D across seven patient groups. Health Econ. 2004;13:873-84.

14. Kaarlola A, Pettila V, Kekki P. Performance of two measures of general health-related quality of life, the EQ-5D and the RAND-36 among critically ill patients. Intensive Care Med. 2004;30:2245-52.

15. Bharmal M, Thomas J, III. Comparing the EQ-5D and the SF-6D descriptive systems to assess their ceiling effects in the US general population. Value Health 2006;9:262-271

16. Hinz A, Klaiberg A, Brahler E, Konig HH. The quality of life questionnaire EQ5D: modelling and norm values for the general population. Psychother Psychosom Med Psychol. 2006;56:48.

17. Krahn M, Bremner KE, Tomlinson G, Ritvo P, Irvine J, Naglie G. Responsiveness of disease-specific and generic utility instruments in prostate cancer patients. Qual Life Res. 2007;16:509-22.

18. Xin Y, Mclntosh E. Assessment of the construct validity and responsiveness of preference-based quality of life measures in people with Parkinson's: a systematic review. Qual Life Res. 2017;26:1-23.

19. Fransen M, Edmonds J. Reliability and validity of the EuroQol in patients with osteoarthritis of the knee. Rheumatology (Oxford). 1999;38:807-13.

20. Dolan P. Modeling valuations for EuroQol health states. Med Care. 1997; 35:1095-108.

21. Horsman J, Furlong W, Feeny D, Torrance G. The health utilities index (HUI): concepts, measurement properties and applications. Health Qual Life Outcomes. 2003:1:54.

22. Brazier J, Roberts J, Deverill M. The estimation of a preference-based measure of health form the SF-36. J Health Econ. 2002;21:292.

23. Herdman M, Gudex C, Lloyd A, Janssen M, Kind P, Parkin D, et al. Development and preliminary testing of the new five-level version of EQ-5D (EQ-5D-5L). Qual Life Res. 2011;20:1727-36.

24. Pickard AS, De Leon MC, Kohlmann T, Cella D, Rosenbloom S. Psychometric comparison of the standard EQ-5D to a 5 level version in cancer patients. Med Care. 2007:45:259-63.

25. Kim SH, Kim HJ, Lee SI, Jo MW. Comparing the psychometric properties of the EQ5D-3L and EQ-5D-5L in cancer patients in Korea. Qual Life Res. 2012;21:1065-73.

26. Jia YX, Cui FQ, Li L, Zhang DL, Zhang GM, Wang FZ, et al. Comparison between the EQ-5D-5L and the EQ-5D-3L in patients with hepatitis B. Qual Life Res. 2014;23:2355-63.

27. Greene ME, Rader KA, Garellick G, Malchau H, Freiberg AA, Rolfson O. The EQ-5D-5L improves on the EQ-5D-3L for health-related quality-of-life assessment in patients undergoing Total hip Arthroplasty. Clin Orthop Relat Res. 2015;473:3383-90

28. Kim TH, Jo MW, Lee SI, Kim SH, Chung SM. Psychometric properties of the EQ5D-5L in the general population of South Korea. Qual Life Res. 2013;22:2245-53.

29. Agborsangaya CB, Lahtinen M, Cooke T, Johnson JA. Comparing the EQ-5D$3 \mathrm{~L}$ and $5 \mathrm{~L}$ : mesaurement properties and association with chronic conditions and multimorbidity in the general population. Health Qual Life Outcomes. 2014:12:74-80.

30. Feng Y, Devlin N, Herdman M. Assessing the health of the general population in England: how do the three- and five-level versions of EQ-5D compare? Health Qual Life Outcomes. 2015;13:171.

31. Scalone L, Cortesi PA, Ciampichini R, Cesana G, Mantovani LG. Health related quality of life norm data of the general population in Italy: results using the EQ-5D-3L and EQ-5D-5L instruments. Epidemiol Biostat Public Health. 2015;12:e11457-1-e11457-15.

32. Direcció General de Regulació PiRS Enquesta de salut de Catalunya. Període 2010-2014. Fitxa tècnica. 2nd. Departament de Salut. Generalitat de Catalunya.; 2012. http://salutweb.gencat.cat/ca/el_departament/ 
estadistiques_sanitaries/enquestes/esca/resultats_enquesta_salut_catalunya/. Accessed 20 January 2017.

33. Badia X, Roset M, Herdman M, Kind P. A comparison of United Kingdom and Spanish general population time trade-off values for EQ-5D health states. Med Decis Mak. 2001;21:7-16.

34. van Hout B, Janssen MF, Feng YS, hImann T, sschbach J, olicki D, et al. Interim scoring for the EQ-5D-5L: mapping the EQ-5D-5L to EQ-5D-3L value sets. Value Health. 2012;15:708-15.

35. Domingo-Salvany A, Regidor E, Alonso J, Alvarez-Dardet C. Proposal for a social class measure. Working Group of the Spanish Society of epidemiology and the Spanish Society of Family and Community Medicine. Aten Primaria. 2000;25:350-63.

36. Heeringa SG, West BT. Berglund PA applied survey data analysis. London: chapman and hall//CRC press. Taylor \& Francis Group; 2010.

37. Janssen MF, Birnie E, Haagsma JA, Bonsel GJ. Comparing the standard EQ5D three-level system with a five-level version. Value Health. 2008;11:275-84.

38. Shannon CE. The mathematical theory of communication. 1963. MD Comput. 1997;14:306-17.

39. Janssen MF, Pickard AS, Golicki D, Gudex C, Niewada M, Scalone L, et al. Measurement properties of the EQ-5D-5L compared to the EQ-5D-3L across eight patient groups: a multi-country study. Qual Life Res. 2013;22:1717-27.

40. Pattanaphesaj J, Thavorncharoensap M. Measurement properties of the EQ5D-5L compared to EQ-5D-3L in the Thai diabetes patients. Health Qual Life Outcomes. 2015;13:14-21.

41. Ramos-Goni JM, Craig BM, Oppe M, Ramallo-Fariña Y, Pinto-Prades JL, Luo $\mathrm{N}$, et al. How to handle data quality issues in EQ-5D-5L valuation studies. The Spanish case [abstract]. Value Health. 2016;19:A376.

42. Garcia-Gordillo MA, Adsuar JC, Olivares PR. Normative values of EQ-5D-5L: in a Spanish representative population sample from Spanish health survey. Qual Life Res. 2016;25:1313-21.

43. Vaupel JW, Zhang Z, van Raalte AA. Life expectancy and isparity: an international comparison of life table data. BMJ Open. 2011;1:e000128.

Ready to submit your research? Choose BMC and benefit from:

- fast, convenient online submission

- thorough peer review by experienced researchers in your field

- rapid publication on acceptance

- support for research data, including large and complex data types

- gold Open Access which fosters wider collaboration and increased citations

- maximum visibility for your research: over $100 \mathrm{M}$ website views per year

At $\mathrm{BMC}$, research is always in progress.

Learn more biomedcentral.com/submissions 